\title{
Thyroid status and Treatment Response of Hypothyroid Infertile Women in Tertiary Care Center of Bangladesh
}

\author{
FARZANA DEEBA ${ }^{1}$, PARVEEN FATIMA ${ }^{2}$, JESMINE BANU ${ }^{3}$, SHAKEELA ISHRAT ${ }^{4}$, \\ NURJAHAN BEGUM ${ }^{5}$, SHAHEEN ARAANWARY ${ }^{6}$,
}

\begin{abstract}
:
Objective(s): Aim of this study was to find out the prevalence of hypothyroidism in infertile women as well as to assess their response to treatment.

Materials and methods: This descriptive study was conducted in Infertility unit of Department of Obstetrics and Gynecology, Bangabandhu Sheikh Mujib Medical University, Bangladesh, a tertiary care centre from January 2014 to December 2014. Four hundred women who visited infertility clinic of the department for fertility treatment were the target population for this study.

Routine investigations such as CBC, Blood sugar 2 hours postparandial or GTT, TSH and Prolactin was done. Subclinical hypothyroidism was diagnosed when there was increased TSH and normal FT 4 .

Hypothyroid patients were given Levothyroxin depending upon TSH levels and continued until end of the study. Patients were followed up for six months even if pregnancy was attained.

Results: Out of 400 women $55 \%$ were primary and $45 \%$ were secondary subfertility. Mean duration of infertility was $4.5 \pm 1.2$ years. Ninety two (23\%) patients were hypothyroid. Among them $66(16.5 \%)$ were subclinical hypothyroid and 26 (6.5\%) were frank hypothyroid. The mean TSH levels were $7.34 \pm 2.13 \mu \mathrm{lU} / \mathrm{ml}$, and the mean PRL levels were $52.46 \pm 11.17 \mathrm{ng} / \mathrm{ml}$. Out of 92 infertile women diagnosed as hypothyroidism 75 (81.52\%) women conceived after treatment with drugs for hypothyroidism (dose depending upon severity of hypothyroidism, i.e. TSH levels). More than $90 \%$ women had regular ovulation for consecutive three cycles after initiation of treatment.
\end{abstract}

Conclusion: The normal TSH levels are the pre-requisite for fertilization. The decision to initiate thyroid replacement therapy in both clinical and subclinical hypothyroidism at early stage is justified in infertile women.

Key word: thyroid disorder, hypothyroidism, infertility

Introduction:

Infertility is failure to achieve pregnancy during one year of regular unprotected intercourse ${ }^{1}$

In the general population, it is estimated that $84 \%$ of females would conceive within 1 year of regular unprotected sexual intercourse. This rises cumulatively to $93 \%$ after 3 years ${ }^{2}$.

At least one in six couples needs specialist help at some time in their lives because of infertility and $71 \%$ trying for their first baby. ${ }^{1-2}$

1. Associate Professor, Department of Obstetrics and Gynaecology, Bangabandhu Sheikh Mujib Medical University, Dhaka, Bangladesh

2. Professor of Infertility, Department of Obstetrics and Gynaecology, Bangabandhu Sheikh Mujib Medical University, Dhaka, Bangladesh.

3. Associate Professor infertility, Department of Obstetrics and Gynaecology, Bangabandhu Sheikh Mujib Medical University, Dhaka, Bangladesh

4. Associate Professor, Department of Obstetrics and Gynaecology, Bangabandhu Sheikh Mujib Medical University, Dhaka, Bangladesh

5. Associate Professor, Department of Obstetrics and Gynaecology, Bangabandhu Sheikh Mujib Medical University, Dhaka, Bangladesh 
Thyroid abnormalities affect a considerable portion of the population. ${ }^{3}$ However, the prevalence and the pattern of thyroid disorders depend on ethnic, geographical factors and especially on iodine intake ${ }^{3-4}$. Thyroid hormones are essential for normal growth, sexual development and reproductive function. Dysfunction and anatomic abnormalities of the thyroid are the most common diseases of the endocrine glands. Thyroid hormones have profound effects on reproduction and pregnancy. Thyroid dysfunction is implicated in a broad spectrum of reproductive disorders, ranging from abnormal sexual development to menstrual irregularities and infertility ${ }^{5}$. Although it has been proved that for normal sexual function, thyroid secretion of T3, T4 need to be approximately normal.

Undiagnosed and untreated thyroid disease can be a cause for infertility as well as sub-fertility. Thyroid dysfunction can affect fertility in various ways resulting in anovulatory cycles, luteal phase defect, high prolactin (PRL) levels, and sex hormone imbalances. Therefore, normal thyroid function is necessary for fertility, pregnancy, and to sustain a healthy pregnancy, even in the earliest days after conception. 6,7 Early stages of thyroid dysfunction can lead to subtle change in ovulation and endometrial receptivity, have profound effect on fertility. Awareness of the thyroid status in the infertile couple is crucial, because of its significant, frequent and often reversible or preventable effect on infertility.

Prevalence of hypothyroidism in the reproductive age group is $2-4 \%$ and has been shown to be the cause of infertility and habitual abortion. ${ }^{8,9}$ Hypothyroidism can be easily detected by assessing TSH levels in the blood. A slight increase in TSH levels with normal $\mathrm{T}_{3}$ and $\mathrm{T}_{4}$ indicates subclinical hypothyroidism whereas high TSH levels accompanied by low $\mathrm{T}_{3}$ and $\mathrm{T}_{4}$ levels indicate clinical hypothyroidism ${ }^{10}$. It can cause anovulation directly or by causing elevation in PRL. Many infertile women with hypothyroidism had associated hyperprolactinemia due to increased production of thyrotropin releasing hormone $(\mathrm{TRH})^{11,12 .}$

Measurement of TSH and PRL is routinely done as a part of infertility workup. Due to the lack of populationbased infertility data of women with subclinical hypothyroidism, we planned to study the prevalence of hypothyroidism in infertile women as well as to assess their response to drug treatment for hypothyroidism. So purpose of this study was to evaluate the thyroid status and treatment response of levothyroxin therapy in subfertile women of a tertiary level infertility management center.

\section{Materials and Methods:}

This descriptive study was conducted in a tertiary level infertility unit of Department of Obstetrics and Gynecology, Bangabandhu Sheikh Mujib Medical University, Bangladesh, from January 2014 to December 2014. Four hundred women who visited infertility clinic of the department for fertility treatment were the target population for this study.

Infertile women having tubal blockage, pelvic inflammatory disease, endometriosis on diagnostic laparoscopy, genital TB (PCR-positive); liver, renal or cardiac diseases; those already on treatment for thyroid disorders or hyperprolactinemia; or cases where abnormality was found in husband's semen analysis were excluded from the study.

Routine investigations such as $\mathrm{CBC}$, Blood sugar 2 hours postparandial or GTT where it is applicable, TSH, Prolactin, Ovarian reserve testing ( $\mathrm{FSH}, \mathrm{E} 2$ and $\mathrm{AMH}$ ) where indicated and ultrasound were done.

TSH and PRL were measured by the electrochemiluminesence method as per the instruction manual for Elecsys, 2010 (Roche, USA). Normal TSH and PRL levels were $0.27-5.0 \mathrm{U} / \mathrm{ml}$ and $1.9-25 \mathrm{ng} /$ $\mathrm{ml}$, respectively, as per kit supplier's instruction. Therefore, hypothyroidism was considered at TSH levels of $>5.0 \mu \mathrm{lU} / \mathrm{ml}$ and hyperprolactinemia at PRL levels of $>25 \mathrm{ng} / \mathrm{ml}$ and subclinical hypothyroidism when increased $\mathrm{TSH}_{\mathrm{H}}$ and normal $\mathrm{FT}_{4}$.

Hypothyroid patients were given levothyroxin depending upon TSH levels and continued until end of the study. Patients were followed up for six months even if pregnancy was attained.

The primary endpoint was pregnancy and secondary endpoint were serum TSH, FT4, regular menstruation and ovulation. Sign of ovulation was assessed by TVS, Day21 serum progesterone. Chemical pregnancy when S. B-HCG was $>15 \mathrm{mlU} / \mathrm{ml}$ and clinical pregnancy was confirmed by observing gestational sac with or without embryo with or without visible cardiac activity on USG.

The study was approved by the institutional review board of BSMMU and informed written consent was taken from all patients.

Statistical analysis was done by SPSS package . 


\section{Results:}

Of the 400 women enrolled for the study $55 \%$ were primary and $45 \%$ were of secondary subfertility, mean duration of infertility was $4.5 \pm 1.2$ years. Ninety two (23\%) patients were hypothyroid. Among them 66 (16.5\%) were subclinical hypothyroid and $26(6.5 \%)$ were frank hypothyroid (Table I). The mean TSH levels were $7.34 \pm 2.13 \mu \mathrm{lU} / \mathrm{ml}$, and the mean PRL levels were $52.46 \pm 11.17 \mathrm{ng} / \mathrm{ml}$ (Table II). Out of 92 infertile women diagnosed as hypothyroidism 75 (81.52\%) women conceived after treatment with drugs for hypothyroidism (dose depending upon severity of hypothyroidism, i.e. TSH levels) (Table III). More than $90 \%$ women had regular ovulation for consecutive three cycles after initiation of treatment.

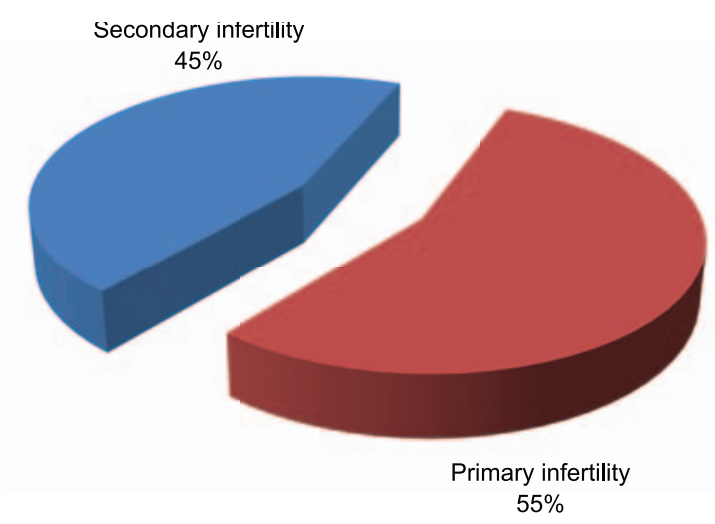

Fig.-1: Type of infertility

Table-I

Patient's Characteristics

\begin{tabular}{lcc}
\hline Variables & Mean & \pm SD \\
\hline Age & 22.3 & \pm 4.6 \\
BMl & 25.2 & \pm 3.1 \\
Mean duration of infertility & 4.5 & \pm 1.2 \\
Thyroid status & $\mathrm{N}$ & $\%$ \\
Euthyroid & 292 & 73 \\
Hyperthyroid & 16 & $4 \%$ \\
Subclinical hypothyroid & 66 & 16.5 \\
Frank hypothyroid & 26 & 6.5 \\
\hline
\end{tabular}

Table-II

Mean hormone level in hypothyroid subjects $(n=92)$

\begin{tabular}{lcc}
\hline Serum Hormones & Mean & \pm SD \\
\hline S.TSH $(\mathrm{mlU} / \mathrm{L})$ & 7.34 & \pm 2.13 \\
S.FT4 $(\mathrm{pmol} / \mathrm{l})$ & 17.34 & \pm 3.23 \\
S. Prolactin $(\mathrm{ng} / \mathrm{ml})$ & 52.46 & \pm 11.17 \\
\hline
\end{tabular}

Table-III

Treatment response of hypothyroid subjects $(n=92)$

\begin{tabular}{lcc}
\hline Outcome & Number & $\%$ \\
\hline Regular menstruation & 88 & 95.6 \\
Ovulation & 84 & 91.3 \\
Clinical pregnancy & 44 & 47.8 \\
Chemical pregnancy & 65 & 70.6 \\
\hline
\end{tabular}

\section{Discussion:}

Hypothyroidism is an important cause of both primary and secondary infertility. Therefore, it is important to predict hypothyroidism during infertility to prevent its occurrence later on. Many reports have described the use of serum thyroid hormones biochemical parameter to predict the development of infertility, but with controversial results ${ }^{12}$.

TSH and PRL levels are usually checked at the time of the couple's initial consultation for infertility. In our study, the prevalence of hypothyroidism was $23 \%$ (subclinical $16.5 \%$ and clinical $6.5 \%$ ) and hyperthyroidism was $4 \%$, which is higher than in USA ${ }^{13}$.

Thyroid hormones have profound effects on reproduction and pregnancy. Thyroid dysfunction is implicated in a broad spectrum of reproductive disorders, ranging from abnormal sexual development to menstrual irregularities and infertility ${ }^{5}$. Although it has been proved that for normal sexual function, thyroid secretion of T3, T4 need to be approximately normal. Undiagnosed and untreated thyroid disease can be a cause for infertility as well as sub-fertility. Problem in fertility can occur at any point in the process of conception that is in the development and release of egg, in fertilization or transportation of the fertilized egg from the fallopian tube to the uterus and in implantation of the embryo in endometrium.

Hormone therapy with thyroxine is the choice of treatment in established hypothyroidism. It normalizes the menstrual cycle, PRL levels and improves the fertility rate. Therefore, with simple oral treatment for hypothyroidism, $47.8 \%$ infertile women conceived after 6 weeks to 6 months of therapy. We tried to maintain normal TSH levels. Compliance and adequacy of hypothyroid drug dose were checked by TSH measurement at 6 to 8 weeks interval. 
Therefore, the normal TSH levels are the pre-requisite for fertilization. The decision to initiate thyroid replacement therapy in subclinical hypothyroidism at early stage is justified in infertile women.

\section{Conclusion:}

Careful diagnosis and treatment of hypothyroidism, can benefit a lot rather than going for unnecessary hormone assays and costly invasive procedures. For better management of infertility cause, we should plan further studies with the large sample size and longterm follow-up, which are necessary to validate the variation in TSH and PRL levels.

\section{References:}

1. Te Velde ER, Eijkemans R, Habbema HDF. Variation in couple fecundity and time to pregnancy, an essential concept in human reproduction. Lancet 2000;355:1928-9.

2. Bongaarts J. A method for the estimation of fecundability. Demography 1975;12:645-60.

3. Sawin CT, Castelli WP, Hershman JM, McNamara, $P$ \& Bacharach $P$. The aging thyroid. Thyroid defciency in the Framingham study. Archives of Internal Medicine 1985;145: 13861388.

4. Canaris GJ, Manowitx NR, Mayor G \& Ridgway EC. The Colorado thyroid disease prevalence study. Archives of Internal Medicine. 2000; 160: 526-534.

5. Trokoudes, krinos M, Skordi S Nicos, Picolos, Michalis K, Pedieos IVF centre and Cyprus: infertility and thyroid disorder. Current opinion in obstetrics and gynecology. 2006; 18(4): 446-451.
6. Poppe K, Velkeniers B, Glinoer D. The role of thyroid autoimmunity in fertility and pregnancy. Nat Clin Pract Endocrinol Metab. 2008;4: 394-405.

7. Poppe K, Velkeniers B. Thyroid disorders in infertile women. Ann Endocrinol.2003;64:45-50.

8. Lincoln R, Ke RW, Kutteh WH. Screening for hypothyroidism in infertile women. J Reprod Med. 1999;44:455-7.

9. Krassas GE. Thyroid disease and female reproduction. Fertil Steril. 2000;74:1063-70.

10. Anderson S, Pederson KM, Bruun NH, Laurberg $P$. Narrow individual variations in serum T4 and T3 in normal subjects; a clue to the understanding of subclinical thyroid disease. J Clin Endocrinol Metab. 2002;87:1068-72.

11. Raber W, Gessl A, Nowotny P, Vierhapper H. Hyperprolactnemia in hypothyroidism; clinical significance and impact of TSH normalization. Clin Endocrinol. 2003;58:185-91.

12. Raber w, Nowotony $p$ and vytiska Binstorfer $E$ and vier happer $\mathrm{H}$ : Thyroxine treatment modified in infertile women according to thyroxine releasing hormone testing: 5 year follow up of 283 women referred after exclusion of absolute causes of infertility. Hum. Reprod 2003;18:707 -14.

13. Olivar AC, Chaffkin LM, Kates RJ, Allan TR, Beller $P$, Graham NJ. Is it necessary to obtain serum levels of thyroid stimulating hormone and prolactin in asymptomatic women with infertility? Conn Med. 2003;67:393-5. 